\title{
PACIENTŲ ŽINIOS APIE DANTŲ EROZIJŲ RIZIKOS VEIKSNIUS
}

\author{
Brigita Kalinauskaitė, Kristina Saldūnaitė, Jūratė Zūbienė, Skaistė Ižganaitienė, \\ Eglè Slabšinskienė, Eglè Aida Bendoraitienè \\ Lietuvos sveikatos mokslu universiteto Medicinos akademijos Odontologijos fakultetas
}

Raktažodžiai: erozinis dantų nusidèvejjimas, dantų erozijos, rizikos veiksniai, žinios, burnos higiena.

\section{Santrauka}

Tyrimo tikslas - ištirti 18-74 metų respondentų žinias apie dantų erozijų rizikos veiksnius ir jų poveiki burnos sveikatai.

Tyrimo medžiaga ir metodai. Tyrimas atliktas Kauno Žaliakalnio dantų klinikoje. Tyrime dalyvavo 101 šios klinikos pacientas. Tyrimo metodas - anketine apklausa.

Gautieji rezultatai parodè, kad teisingą dantų erozijų apibrezžimą žinojo didžioji dalis ( 79,7 proc.) tiriamųjų. Jaunesni (18-29 m. ir 30-44 m.) respondentai, geriau nei vyresni (45-59 m. ir 60-74 m.) žinojo, kad sumažejjęs seilètekis turi poveikị erozijų atsiradimui. Baseinų vandens ir dantų valymo po rūgščių vartojimo poveikis erozijoms išsivystyti buvo žinomas prasčiau. Nustatytas statistiškai reikšmingas ryšys tarp dažno citrinų, apelsinų ar greipfrutų, gazuotų gaiviujų, energinių gèrimų bei vaisių sulčių, rūgščių obuolių, marinuotų maisto produktų vartojimo ir dantų erozijų atsiradimo.

Išvada. Rūgščių maisto produktų ir gėrimų vartojimas yra reikšmingai susijęs su dantų erozijomis, tačiau respondentai neturi pakankamai žinių apie erozijų rizikos veiksnius.

\section{Ivadas}

Dantų erozijos apibūdinamos kaip negrižtamas, cheminio proceso sukeltas, nebakterinès kilmès danties kietujų audinių praradimas [1]. Tai daugelio veiksnių nulemta būklè, dažna kartu su kitomis dantu dilimo formomis, tokiomis kaip atricija, sukeliama dantų tarpusavio kontakto, ar abrazija, atsirandanti dèl abrazyvinio tam tikrų medžiagų poveikio $[1,2]$. Erozinị dantų nusidèvẻjimą sukelia rūgštys, kurios gali būti vidinès ir išorinès kilmès. Vidinès kilmès rūgštys patenka ị burnos ertmę, esant tam tikrai sveikatos būklei, tokiai kaip gastroezofaginis refliuksas (GERL) ar valgymo sutrikimai [1-3]. Išorinès kilmès rūgštys i burną patenka kartu su maistu bei gèrimais (rūgštūs vaisiai, vaisių sultys, gaivieji, energiniai, sportiniai gérimai) [2], tam tikrais vaistais [1,2], jų tiesioginį kontaktą su danties paviršiumi gali lemti laisvalaikio leidimo būdas, aplinka, kurioje individas praleidžia nemažai laiko, pavyzdžiui, plaukimo baseinų vanduo [4].

Daugeliui Europos regionų būdingas didelis dantų erozijos paplitimas $[5,4]$. Tai pagrindinè dantų nusidèvejjimo priežastis, paveikianti visas amžiaus grupes [4]. Tyrimai rodo, kad apie 30 proc. europiečių turi ryškius bent vieno danties erozinius pakitimus $[2,4]$. Daugiau nei 30 proc. 14-mečių paauglių būdingos viršutinių kandžių gomurinių paviršių erozijos [4]. Mūsų šalyje $2017 \mathrm{~m}$. atliktas tyrimas parodè, kad erozijų paplitimas tarp 19-71 metų tiriamujų buvo 44 proc. [6].

Atliktų studijų apžvalga parodè, kad respondentai neturi pakankamai žinių apie dantų erozijų atsiradimo priežastis $[2,7]$.

Darbo tikslas - išanalizuoti 18-74 metų pacientų žinias apie dantų erozijų rizikos veiksnius ir jų poveikị burnos sveikatai.

\section{Tyrimo medžiaga ir metodai}

Vienmomentinis tyrimas buvo vykdomas nuo $2018 \mathrm{~m}$. gruodžio 3 d. iki 2019 m. vasario 28 d. Kauno Žaliakalnio dantų klinikos pacientams. Tyrime dalyvavo 101 respondentas, parinktas atsitiktinès atrankos būdu (1 lentelè).

Tyrimui sudarytas modifikuotas klausimynas, remiantis kitais atliktais tyrimais $[2,6]$. Uždaro ir atviro tipo klausimai buvo netiesiogiai suskirstyti ị penkias dalis: pirmoji dalis skirta demografiniams duomenims surinkti (lytis, amžius, išsilavinimas); antroji - patikrinti respondentų žinias apie dantų erozijas (erozijos apibrèžimas, jos raiška burnoje, ją sukeliančios priežastys ir rizikos veiksniai); trečioji dalis skirta išsiaiškinti, kokie dantų erozijos rizikos veiksniai veikia tyrimo dalyvius (GERL, anoreksija, bulimija, rūgštaus maisto ir gèrimų, vaistų vartojimo dažnis, plaukimo baseinų 
lankymas); ketvirtoji dalis susijusi su respondentų burnos priežiūros ypatumais (dantų valymo dažnis, laikas, šepetèlio ir dantų pastos pasirinkimas, papildomų burnos priežiūros priemonių naudojimas); penktoji dalis skirta respondentų nusiskundimams ir lankymosi pas burnos priežiūros specialistą priežastims bei dažniui išsiaiškinti.

Tyrimui vykdyti gautas Lietuvos sveikatos mokslų universiteto Medicinos akademijos Bioetikos komisijos pritarimas (Nr. BEC-BH(B)-24).

Statistinè tyrimo duomenų analizè atlikta naudojant SPSS (angl. - Statistical package for the social sciences) 20.0 versijos programini paketą. Gautų kintamųjų įvertinimui taikyti aprašomosios statistikos metodai. Duomenys pateikiami procentais ir dažniais. Statistiškai reikšmingiems skirtumams buvo taikytas chi-kvadrato $\chi^{2}$ kriterijus ir jo reikšmingumas $p$. Ryšiams nustatyti - Spirmeno (Spearman's) koreliacijos koeficientas $r$. Pasirinktas reikšmingumo lygmuo $p=0,05$ [8].

\section{Rezultatai ir jų aptarimas}

Anketinès apklausos duomenys parodè, kad didžioji dalis respondentų (79,7 proc.) buvo teisūs, manydami, jog dantų erozija yra cheminès kilmès danties kietujų audinių praradimas, atsirandantis dèl rūgščių poveikio. Nyderlanduose vykdytos studijos dalyvių žinios buvo kiek prastesnès - tik

1 lentelè. Respondentų pasiskirstymas pagal sociodemografinius veiksnius $(\mathrm{n}=101)$.

\begin{tabular}{|l|c|c|c|}
\hline \multicolumn{2}{|l|}{ Veiksniai } & n & proc. \\
\hline \multirow{2}{*}{ Lytis } & Vyras & 46 & 45,5 \\
\cline { 2 - 4 } & Moteris & 55 & 54,5 \\
\hline Iš viso: & 101 & 100 \\
\hline \multirow{3}{*}{ Amžiaus grupès } & $18-29 \mathrm{~m}$. & 30 & 29,7 \\
\cline { 2 - 4 } & $30-44 \mathrm{~m}$. & 28 & 27,7 \\
\cline { 2 - 4 } & $45-59 \mathrm{~m}$. & 27 & 26,7 \\
\cline { 2 - 4 } & $60-74 \mathrm{~m}$. & 16 & 15,8 \\
\hline
\end{tabular}

pusė apklausos dalyvių (52 proc.) sutiko, jog tai yra teisingas šios būklès apibrèžimas [2].

Dauguma tiriamujų, prašomi nurodyti maisto produktus ir gèrimus, jų manymu, galinčius sukelti erozijas, teisingai nurode gaiviuosius gerimus ( 72,3 proc.) ir citrusinius vaisius (79,2 proc.). Didelè dalis tiriamujų buvo teisūs, manydami, kad sūris (88,1 proc.), jogurtas (90,1 proc.), pienas $(91,1$ proc.) ir vanduo (98 proc.) neskatina dantų erozijų. Kiek mažiau buvo žinomas obuolių (34,7 proc.) ir sportinių gèrimų (43,6 proc.) erozinis poveikis dantims. Reikšmingai dažniau vyrai (19,6 proc.), nei moterys (5,5 proc.), manè, kad sūris gali sukelti dantų erozijas $(p<0,05)$. Panašǔs ir kito mokslinio tyrimo rezultatai, kurio dalyviai dažniausiai nurodè vaisių sultis (88 proc.), sportinius (92 proc.), energinius (97 proc.) ir gaiviuosius gèrimus (97 proc.), kaip darančius poveiki dantų erozijų atsiradimui, vandeni (99 proc.) - kaip neturintị tokio poveikio, tačiau, kiek mažiau (61 proc.) respondentu žinojo apie obuolių erozinị poveikị dantims [2]

Du trečdaliai (67,3 proc.) respondentų teisingai mané, kad gèrimas iš stiklinès, gurkšnị ilgiau palaikant burnoje, daro didesnị poveikị erozijų atsiradimui. Reikšmingai dažniau vyrai, negu moterys, manè, kad dantų valymas išgèrus stiklinę sulčių, gali sukelti dantų eroziją $(p<0,05)(2$ lentelè).

Nustatyta, kad dažniau 30-44 (78,6 proc.) ir 18-29 metu (66,7 proc.) amžiaus grupių respondentai manè, kad sumažèjęs seilètekis turi poveikị dantų erozijų atsiradimui, negu 60-74 (56,3 proc.) ar 45-59 metų (37 proc.) amžiaus grupių respondentai $(\mathrm{p}<0,01)$. Kiti moksliniai tyrimai parodè, kad

2 lentelè. Dantų valymo, išgèrus sulčių, erozinio poveikio tikimybès vertinimas (lyčių atžvilgiu). $\left(\chi^{2}=3,9 ; 11 s=3 ; p<0,05\right)$

\begin{tabular}{|l|l|c|c|c|c|}
\hline \multicolumn{2}{|l|}{ Kintamieji } & \multicolumn{2}{|c|}{ Taip } & \multicolumn{2}{c|}{ Ne } \\
\cline { 3 - 7 } \multicolumn{2}{|l}{ Lytis } & n & proc. & N & proc. \\
\hline \multirow{3}{*}{} & moterys & 24 & $\mathbf{5 2 , 2}$ & 22 & 47,8 \\
\cline { 3 - 7 } & 18 & $\mathbf{3 2 , 7}$ & 37 & 67,3 \\
\hline
\end{tabular}

3 lentelè. Rizikingų maisto produktų vartojimo dažnis, esant nustatytoms dantų erozijoms.

\begin{tabular}{|c|c|c|c|c|c|c|c|c|c|c|c|c|}
\hline \multirow[t]{2}{*}{$\begin{array}{l}\text { Maisto } \\
\text { produktai }\end{array}$} & \multirow{2}{*}{$\begin{array}{l}\text { Nustaty- } \\
\text { tos dantu } \\
\text { erozijos }\end{array}$} & \multicolumn{2}{|c|}{ Kasdien } & \multicolumn{2}{|c|}{ 3-5 k./sav. } & \multicolumn{2}{|c|}{ 1-2 k./sav. } & \multicolumn{2}{|c|}{$1-2 \mathrm{k} . / \mathrm{mèn}$} & \multicolumn{2}{|c|}{$\begin{array}{l}\text { Nevar- } \\
\text { toja }\end{array}$} & \multirow[t]{2}{*}{$\chi^{2}$, Ils, $\mathbf{p}$} \\
\hline & & $\mathbf{N}$ & proc. & $\mathbf{N}$ & proc. & $\mathbf{N}$ & proc. & $\mathbf{N}$ & proc. & $\mathbf{N}$ & proc. & \\
\hline \multirow[t]{2}{*}{ Citrinos } & Taip & - & - & 5 & 25 & 9 & 45* & 5 & 25 & 1 & 5 & \multirow{2}{*}{$\begin{array}{c}\chi^{2}=11,666 ; 11 \mathrm{~s}=4 ; \\
\mathrm{p}<0,02\end{array}$} \\
\hline & $\mathrm{Ne}$ & 1 & 1,2 & 1 & 8,6 & 17 & 21* & 40 & 49,4 & 16 & 19,8 & \\
\hline \multirow{2}{*}{$\begin{array}{l}\text { Apelsinai ar } \\
\text { greipfrutai }\end{array}$} & Taip & 5 & $25^{*}$ & 5 & 25 & 3 & 15 & 6 & 30 & 1 & 5 & \multirow{2}{*}{$\begin{array}{c}\chi^{2}=13,425 ; 11 s=4 ; \\
p<0,01\end{array}$} \\
\hline & $\mathrm{Ne}$ & 5 & $6,2 *$ & 6 & 7,4 & 21 & 25,9 & 35 & 43,2 & 14 & 17,3 & \\
\hline \multirow{2}{*}{$\begin{array}{l}\text { Rūgštūs } \\
\text { obuoliai }\end{array}$} & Taip & 5 & $26,3^{*}$ & 5 & 26,3 & 5 & 26,3 & 3 & 15,8 & 1 & 5,3 & \multirow{2}{*}{$\begin{array}{c}\chi^{2}=19,488 ; 11 \mathrm{~s}=4 \\
\mathrm{p}<0,01\end{array}$} \\
\hline & $\mathrm{Ne}$ & 3 & $3,7 *$ & 8 & 9,9 & 15 & 18,5 & 30 & 37 & 25 & 30,9 & \\
\hline \multirow{2}{*}{$\begin{array}{l}\text { Marinuoti } \\
\text { produktai }\end{array}$} & Taip & 1 & 5 & 5 & $25^{*}$ & 3 & 15 & 7 & 35 & 4 & 20 & \multirow{2}{*}{$\begin{array}{c}\chi^{2}=12,071 ; 11 \mathrm{~s}=4 ; \\
\mathrm{p}<0,02\end{array}$} \\
\hline & $\mathrm{Ne}$ & 1 & 1,2 & 3 & $3,7 *$ & 20 & 24,7 & 29 & 35,8 & 28 & 34,6 & \\
\hline
\end{tabular}


tik 37 proc. jauno amžiaus (20-25 m.) respondentų žinojo apie sumažèjusio seilètėkio poveikị [2].

Analizuojant tyrimo duomenis pastebèta, kad didžioji dalis tiriamujų buvo teisūs, manydami, jog dažnas vėmimas gali sukelti dantų erozijas. Trečdalis galvojo, kad baseinų vanduo skatina dantų erozijų vystymąsi (1 pav.).

Ivertinus apklausos rezultatus paaiškèjo, kad dažniau plaukimo baseiną lanko tie, kurie jaučia dantų jautrumą $(22,6$ proc.), negu tie, kurie dantu jautrumo problemų neturi $(4,2$ proc.) ( $<<0,01)$. Tyrimas parode, kad plaukimo baseino lankymas nesusijęs su eroziniais dantų pažeidimais, tačiau aptiktas kitas statistiškai reikšmingas ryšys: baseino vanduo gali sukelti dantų jautrumą $(p<0,01)$. Tai leistų įtarti, jog plaukimo baseinų lankytojams gali formuotis dar nediagnozuotos erozijos. Kitų studijų rezultatai taip pat parodo padidejusią

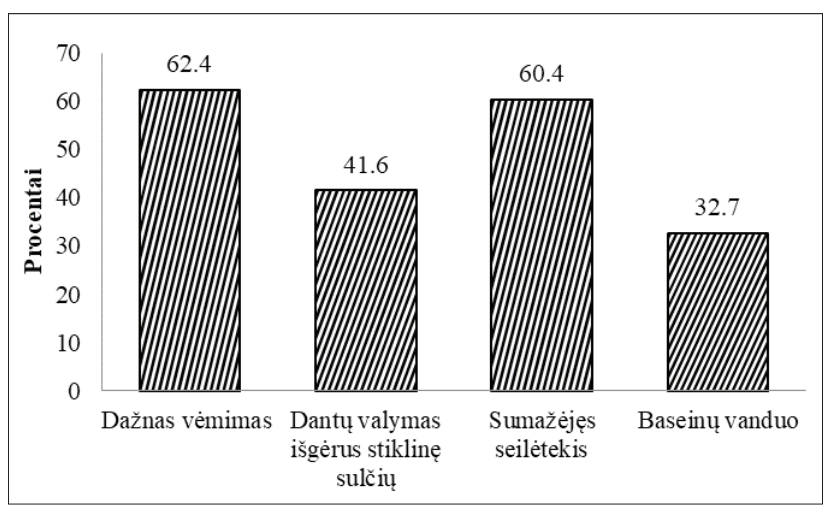

1 pav. Tiriamujų nuomonės apie galimas dantų erozijos priežastis dažnis, proc. profesionalių plaukikų dantų erozijų riziką $[9,10]$.

Šiame tyrime nebuvo nustatytas GERL bei dažno vèmimo poveikis dantų erozijų atsiradimui $(\mathrm{p}>0,05)$, tačiau kiti tyrejai nustate GERL ir erozijų $[6,9]$ bei vemimo ir dantų erozijų ryšius $[11,12]$.

Maždaug 19,8 proc. mūsų tyrimo respondentų gydytojai odontologai ar burnos higienistai yra diagnozavę dantų erozijas. Tyrimas parodè, kad dažniausi nusiskundimai yra dantų jautrumas vartojant rūgštų ar saldų maistą, ypač - gèrimus $(52,5$ proc.) ir dantenų kraujavimas, valant dantis šepetèliu (46,5 proc.). Tik 15,8 proc. respondentų nusiskundimų dèl burnos būklès neturèjo. $2017 \mathrm{~m}$. Lietuvoje atliktame tyrime nustatytas 44 proc. erozijų paplitimas tarp 19-71 metų asmenų [6]. Interpretuojant tokị rezultatų skirtumą, reikia žinoti, kad mūsų studijos metu nebuvo atliktas klinikinis tyrimas, o remtasi anketinès apklausos duomenimis, tad galima manyti, jog realus dantų erozinių pažeidimų paplitimas tirtoje populiacijoje gali būti didesnis. Atlikti klinikiniai tyrimai Suomijoje, Latvijoje ir Estijoje parodė erozijų paplitimą 18 procentų. Didesnis paplitimas nustatytas Didžiojoje Britanijoje - 54 proc., Lenkijoje - 42,3 proc. [13].

Reikšmingai dažniau vyrai (71,7 proc.), negu moterys (36,4 proc.), nurodè, kad jaučia dantų jautrumą $(\mathrm{p}<0,01)$. Vyrai (63 proc.), dažniau negu moterys (32,7 proc.), jautė dantenų kraujavimą, valydami dantis šepetėliu $(p<0,01)$.

Mūsų tyrimas parodè pacientų, kuriems buvo nustatytos dantų erozijos, reikšmingai dažnesnị dantų jautrumą, negu tiems, kuriems jos nenustatytos $(\mathrm{p}<0,05)(2$ pav. $)$

Nustatyta, kad citrinas 1-2 kartus per savaitę dažniau valgo tie respondentai, kuriems nustatytos dantų erozijos,

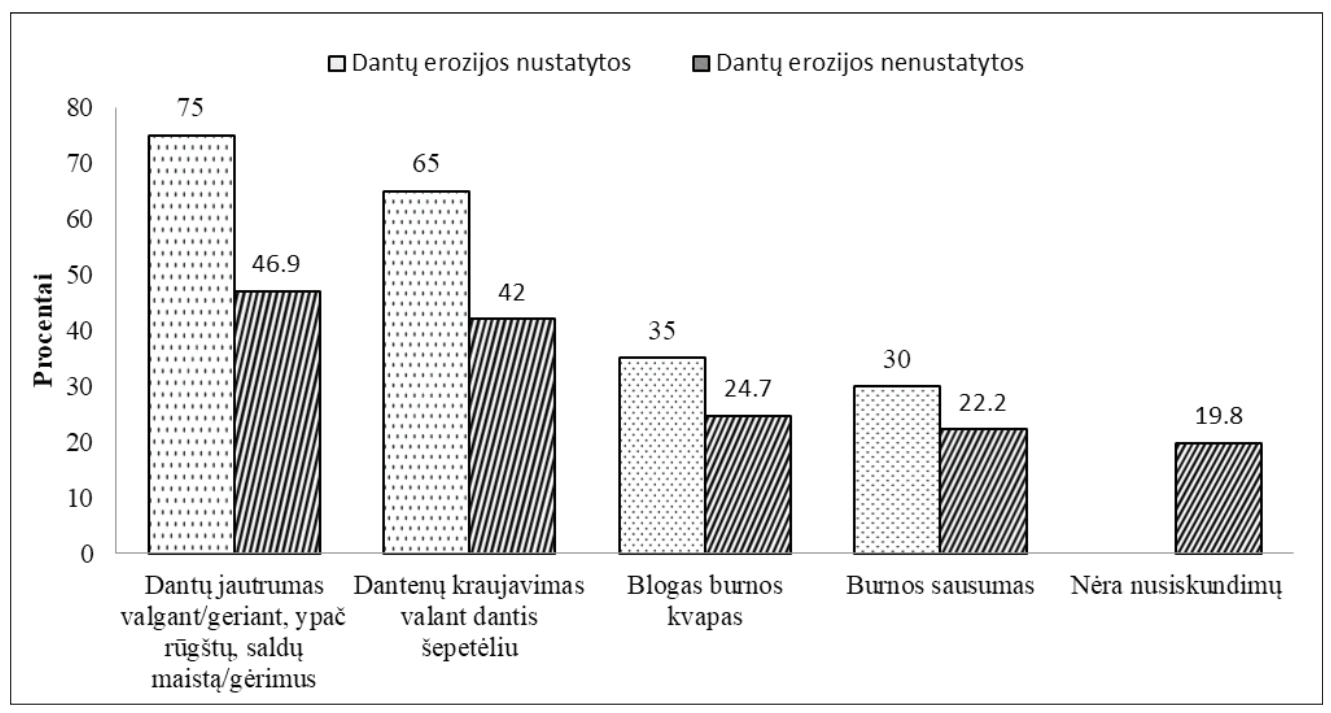

2 pav. Tiriamųų nusiskundimai dèl burnos būklès, proc. $\left(\chi^{2}=5,074 ; 1 l s=1 ; p<0,03\right)$ 
negu tie, kuriems nenustatytos $(\mathrm{p}<0,02)$. Apklausos duomenys parodè, kad tie, kuriems nustatytos dantų erozijos, dažniau kasdien valgo apelsinus ar greipfrutus, negu tie, kuriems jos nenustatytos $(p<0,01)$. Pastebeta, kad turintieji dantų erozijų, dažniau kasdien valgo rūgščius obuolius, nei šių erozijų neturintys $(p<0,01)$. Dažniau marinuotus produktus 3-5 k./sav. vartoja tie, kuriems nustatytos dantų erozijos, negu tie, kuriems nenustatytos $(\mathrm{p}<0,02)(3$ lentelè). Erozinis minètų vaisių poveikis nurodomas mokslinèje literatūroje [5].

Analizuojant tyrimo rezultatus, nustatyti statistiškai reikšmingi ryšiai tarp amžiaus ir gazuotų gaiviưjų $(r=0,303$; $\mathrm{p}<0,01)$ bei energinių gèrimų vartojimo dažnio $(\mathrm{r}=0,257$; $\mathrm{p}<0,01)$. Galima teigti, kad kuo tiriamasis jaunesnis, tuo dažniau vartoja gaiviuosius ir energinius gèrimus.

Tyrimas parodè, kad reikšmingai dažniau (3-5 k./sav.) gaiviuosius gazuotus ( 40 proc.) ir energinius gèrimus (20 proc.) vartoja tie, kuriems nustatytos dantų erozijos, negu tie, kuriems nenustatytos (atitinkamai 7,4 proc. ir 2,5 proc.) ( $p<0,01$ ). Dažniau (25 proc.) 3-5 kartus per savaitę apelsinų ar greipfrutų sultis vartoja tie, kuriems nustatytos dantų erozijos, negu tie, kuriems nenustatytos $(3,7$ proc.) $(\mathrm{p}<0,01)$. Anksčiau atlikti tyrimai patvirtina, kad dažnas tokių gėrimų vartojimas skatina dantų erozijas [1], tačiau vienos studijos rezultatai parodè, jog rūgščių gèrimų vartojimas nèra erozinio dantų pažeidimo rizikos veiksnys [6]. Šiuos nesutapimus galejjo lemti skirtingi respondentų mitybos ịpročiai, nevienodas gèrimų vartojimo dažnis.

Daugelio tyrimo dalyvių burnos higienos ịpročiai buvo netinkami: tik 41,6 proc. repondentų nurodè, kad naudoja šepetėlį minkštais šereliais. Tik apie pusè tiriamujų nurodè naudojantys tarpdančių higieninị siūlą ar tarpdantinị šepetèlị. Netinkamas burnos higienos priemonių naudojimas gali turèti poveikị dantų erozijų atsiradimui [14].

Dantu pastos pasirinkimas bei burnos sausumas šioje studijoje nelèmè dantų erozijų, bet kiti tyrimai parodè priešingus rezultatus: nustatyta, kad balinančios pastos turi dideli abrazyvinį poveikị rūgščiu paveiktam emalio paviršiui, todèl greitina patologinị dantų dilimą [15]. Irodyta, kad asmenims, jaučiantiems burnos sausumą, didesnè dantų erozijos rizika [16].

\section{Išvados}

1. Respondentai per mažai turi žinių apie dantų erozijas ir jų priežastis.

2. Vyrai (52,2 proc.), geriau nei moterys (32,7 proc.), žino, jog dantų valymas iš karto po kontakto su rūgštimis skatina erozinius dantų pažeidimus, o jaunesni respondentai, geriau nei vyresni, žino, kad sumažèjęs seilètekis - dantų erozijų rizikos veiksnys.
3. Rūgščių maisto produktų ir gėrimų vartojimas yra reikšmingai susijęs su dantų erozijų išsivystymu.

\section{Literatūra}

1. Skalsky Jarkander M, Grindefjord M, Carlstedt K. Dental erosion, prevalence and risk factors among a group of adolescents in Stockholm County. Eur Arch Paediatr Dent 2018;19(1):23-31. https://doi.org/10.1007/s40368-017-0317-5

2. Verploegen VJN, Schuller AA. Erosive tooth wear: knowledge among young adults and their preferred information sources Int J Dent Hyg 2018;1-8.

https://doi.org/10.1111/idh.12367

3. Frazao JB, Machado LG, Farreira MC. Dental erosion in schoolchildren and associated factors: a cross-sectional study. J Indian Soc Pedod Prev Dent 2018;36(2):113-9. https://doi.org/10.4103/JISPPD.JISPPD_1041_17

4. Paryag A, Rafeek R. Dental erosion and medical conditions: an overview of aetiology, diagnosis and management. West Indian Med J 2014;63(5):499-502.

https://doi.org/10.7727/wimj.2013.140

5. Carvalho ST, Colon P, Ganss C, Huysmans MC, Lussi A, Schlueter N, Schmalz G, Shellis PR, Tveit AB, Wiegand A. Consensus report of the European Federation of conservative dentistry: erosive tooth wear - diagnosis and management. Swiss Dent J 2016;126:342-346.

6. Ambrulaitytè G. Faktoriai, lemiantys patologinị dantų dilimą. Magistro darbas. Kaunas, 2017.

7. Aggarwal VR, Javidi H, Joughin A, Crawford FI, Sharif MO. Patients' knowledge of risk factors for dental disease. A pilot service evaluation in a general dental practice. Prim Dent Care 2010;17(4):173-7.

https://doi.org/10.1308/135576110792936159

8. Sapagovas J., Šaferis V., Jurènienė K., Jurkonienė R., Šimatonienè V., Šimoliūnienè R. Statistikos ir informatikos pagrindai. KMU, 2007; 65.

9. Zebrauskas A, Birskute R, Maciulskiene V. Prevalence of dental erosion among the young regular swimmers in Kaunas, Lithuania. J Oral Maxillofac Res 2014;5(2):e6.

https://doi.org/10.5037/jomr.2014.5206

10. Buczkowska-Radlińska J, Łagocka R, Kaczmarek W, Górski M, Nowicka A. Prevalence of dental erosion in adolescent competitive swimmers exposed to gas-chlorinated swimming pool water. Clin Oral Investig 2013;17(2):579-583.

https://doi.org/10.1007/s00784-012-0720-6

11. Dynesen AW, Gehrt CA, Klinker SE, Christensen LB. Eating disorders: experiences of and attitudes toward oral health and oral health behavior. Eur J Oral Sci 2018;126(6):439-542.

https://doi.org/10.1111/eos.12578

12. Otrsu M, Hamura A, Ishikawa Y, Karibe H, Ichijyo T, Yoshinaga Y. Factors affecting the dental erosion severity of patients with eating disorders. Biopsychosoc Med 2014;8:25. 
https://doi.org/10.1186/1751-0759-8-25

13. Strużycka I, Lussi A, Bogusławska-Kapała A, Rusyan E. Prevalence of erosive lesions with respect to risk factors in a young adult population in Poland a cross-sectional study. Clin Oral Investig 2017;21(7):2197-2203. https://doi.org/10.1007/s00784-016-2012-Z

14. Wei Z, Du Y, Zhang J, Tai B, Du M, Jiang H. Prevalence and indicators of tooth wear among chinese adults. PLoS ONE 2016;11(9):e0162181.

https://doi.org/10.1371/journal.pone.0162181

15. Mosquim V, Martines Souza B, Foratori Junior GA, Wang L, Magalhães AC.The abrasive effect of commercial whitening toothpastes on eroded enamel. Am J Dent 2017; 30(3):142-146.

16. Ramsay AS, Rothen M, Scott JM, Cunha-Cruz J. Tooth wear and the role of salivary measures in general practice patients. Clin Oral Investig 2015;19(1):85-95.

https://doi.org/10.1007/s00784-014-1223-4

\section{PATIENT KNOWLEDGE OF RISK FACTORS OF DENTAL EROSION}

B. Kalinauskaitė, K. Saldūnaitė, J. Zūbienė, S. Ižganaitienė, E. Slabšinskienė, E. A. Bendoraitienė

Keywords: erosive tooth wear, dental erosion, risk factors, knowledge, dental hygiene.

Summary

The aim of the work is to evaluate the knowledge of the risk factors of dental erosion and their effects on oral health in adults aged $18-71$ years.

Materials and methods: 101 patients visiting Zaliakalnis Dental Clinic in Kaunas were enrolled in this study. The research was conducted using the anonymous questionnaire.

Results showed that the majority $(79,7 \%)$ of respondents knew the correct definition of dental erosions. Younger respondents ( $18-29$ and $30-44$ years) better knew that reduced salivation had an impact on the development of erosions than older people ( $45-59$ and $60-74$ years). The influence of pool water and tooth brushing after the contact of acids was less known. A statistically significant relationship was found between frequent consumption of citrines, oranges/ grapefruits, apples, pickled foods, carbonated soft drinks, energy drinks, fruit juices and dental erosions.

Conclusions: the use of acidic foods and beverages is significantly associated with dental erosions, however, respondents do not have sufficient knowledge of risk factors of dental erosion.

Correspondence to: brigitakalinauskaite@gmail.com

Gauta 2019-11-18 